\title{
Isopycnal and Diapycnal Mixing at the Cape Verde Frontal Zone
}

\author{
BiRGIT KLEIN* AND GEROLD SIEDleR \\ Institut für Meereskunde an der Universität Kiel, Kiel, Germany \\ (Manuscript received 28 March 1994, in final form 3 November 1994)
}

\begin{abstract}
The Cape Verde Frontal Zone separates the North and the South Atlantic Central Waters in the eastern North Atlantic. It also represents the boundary between the ventilated subtropical gyre and the quasi-stagnant shadow zone in the southeast. The thermohaline front is nearly compensated with respect to density, and density parameters $R_{p}$ suggest the existence of double-diffusive processes. Datasets from three cruises to the region, approximately one year apart each, are used to determine the effects of double-diffusive diapycnal versus isopycnal mixing. For this purpose results from the usual temperature-salinity analysis assuming isopycnal mixing are compared to results from a multiparameter analysis where nutrient and oxygen data are also used. Significant diapycnal fluxes are found in the frontal zone between 200 and $300 \mathrm{~m}$, with water mass contents being changed by more than $20 \%$ through diapycnal mixing. The associated buoyancy fluxes have a similar magnitude as surface fluxes in the area and thus represent an important contribution to the vertical balances of heat and salt.
\end{abstract}

\section{Introduction}

The Cape Verde Frontal Zone was named by Zenk et al. (1991) when describing a major discontinuity in the warm water sphere in the eastern tropical Atlantic. It marks the boundary between the North and South Atlantic Central Waters (NACW, SACW) that form a remarkably strong thermohaline front north of the Cape Verde Islands. The Central Water boundary extends over the whole Atlantic but most of the studies of the thermohaline front have been conducted near the West African shelf associated with upwelling investigations. From these studies (Hagen et al. 1986; Hagen and Schemainda 1987; Barton 1987) it is evident that SACW is carried poleward along the African coast by the upwelling undercurrent and reaches as far north as $20^{\circ} \mathrm{N}$. Investigations by Manriquez and Fraga (1982) suggested that in the open ocean frontal meanders in the order of $350 \mathrm{~km}$ have to be expected. The Central Water boundary separates the well-ventilated waters of the subtropical gyre in the north from more stagnant waters in the south. It is located on the southern side of the Canary Current, a current shown to be baroclinically unstable by the model results of Onken and

*Current affliation: Universität Bremen, Abt. Tracer-Ozeanographie, Bremen, Germany.

Corresponding author address: Dr. Birgit Klein, Universität Bremen, Institut für Umweltphysik, Abt. Tracer-Ozeanographie, Kufsteiner Str., 28359 Bremen, Germany.
Klein (1991). By this process an eddy field is produced with scales of the order of $100 \mathrm{~km}$ and 100 days, respectively, providing an additional structure to the overall complicated property distributions in this area.

The aim of this study is to separate isopycnal and diapycnal mixing in the frontal zone. Earlier attempts to determine turbulent vertical mixing rates directly from microstructure measurements have indicated only low levels of active mixing in the thermocline (Gregg 1975). This has led to the hypothesis that more intense vertical mixing takes place at ocean boundaries along coasts and islands (Hogg et al. 1978). Both smallscale turbulent mixing and double-diffusion drive fluxes across isopycnals. The general effectiveness of doublediffusive processes in producing vertical fluxes is controversial. While double-diffusive convection has been known for some time to be important in isolated regions of the ocean like the Mediterranean outflow (Tait and Howe 1968) and the northeast Caribbean (Lambert and Sturges 1977), Schmitt and Evans (1978) have been the first to point out the general importance of this mechanism in the Central Waters. Bauer and Siedler (1988) have studied diapycnal fluxes out of the high salinity tongue of the Subtropical Salinity Maximum Water, a water mass that is found above the Central Waters. They concluded that the double-diffusive salt flux is an important process for the salt balance in this water mass and is either balanced by isopycnal advection or isopycnal eddy diffusion.

The density parameter $R_{\rho}$ is often used to characterize the conditions for double-diffusive fluxes. It is defined as 


$$
R_{\rho}=\frac{\alpha T_{z}}{\beta S_{z}}
$$

with $\alpha=-(1 / \rho)(\partial \rho / \partial T)$ the thermal expansion coefficient and $\beta=(1 / \rho)(\partial \rho / \partial S)$ the haline contraction coefficient; $T_{z}$ and $S_{z}$ are the vertical gradients of temperature and salinity.

The strength and time evolution of double-diffusive fluxes is a function of the density parameter $R_{\rho}$, which has to be in a certain range, generally between 1 and 2 (Schmitt and Evans 1978), for a development of significant double-diffusive fluxes. Low values of the density parameter $R_{\rho}$ are a common feature of both the North and South Atlantic Central Waters. Schmitt (1981) calculated values of about 1.9 for the Atlantic, but closer to the Cape Verde Front values observed are even lower than that. With these favorable conditions for double-diffusive processes, one might expect to detect locations of diapycnal mixing.

Most of the temperature and salinity contrast between the Central Waters is compensated in terms of density and thus favors intrusions and interleaving along the front. As a consequence, double-diffusive fluxes may lead to significant diapycnal fluxes in addition to turbulent fluxes. Our aim is to identify regions and depth horizons that show deviations from isopyc-
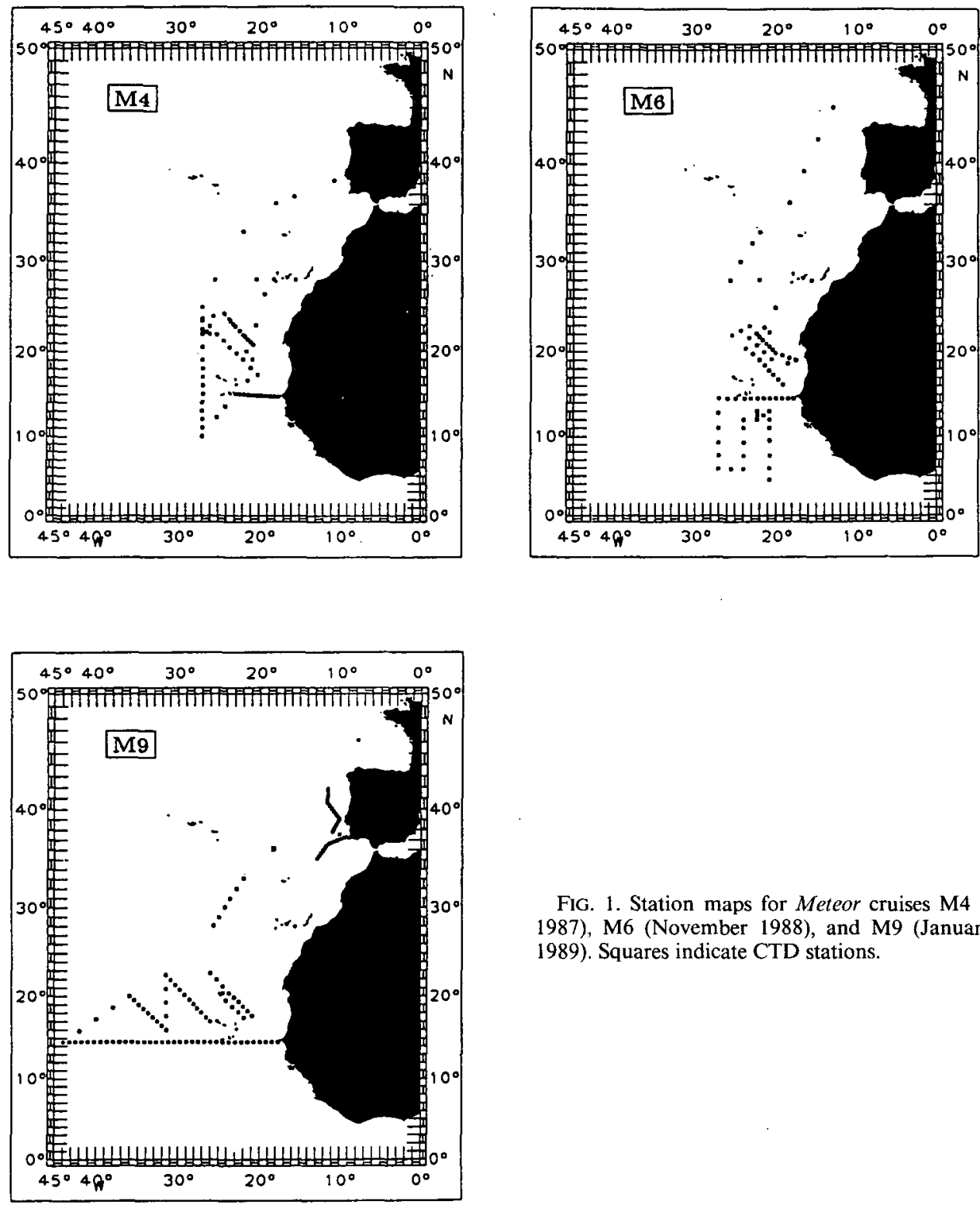

FIG. 1. Station maps for Meteor cruises M4 (November 1987), M6 (November 1988), and M9 (January/February 1989). Squares indicate CTD stations. 

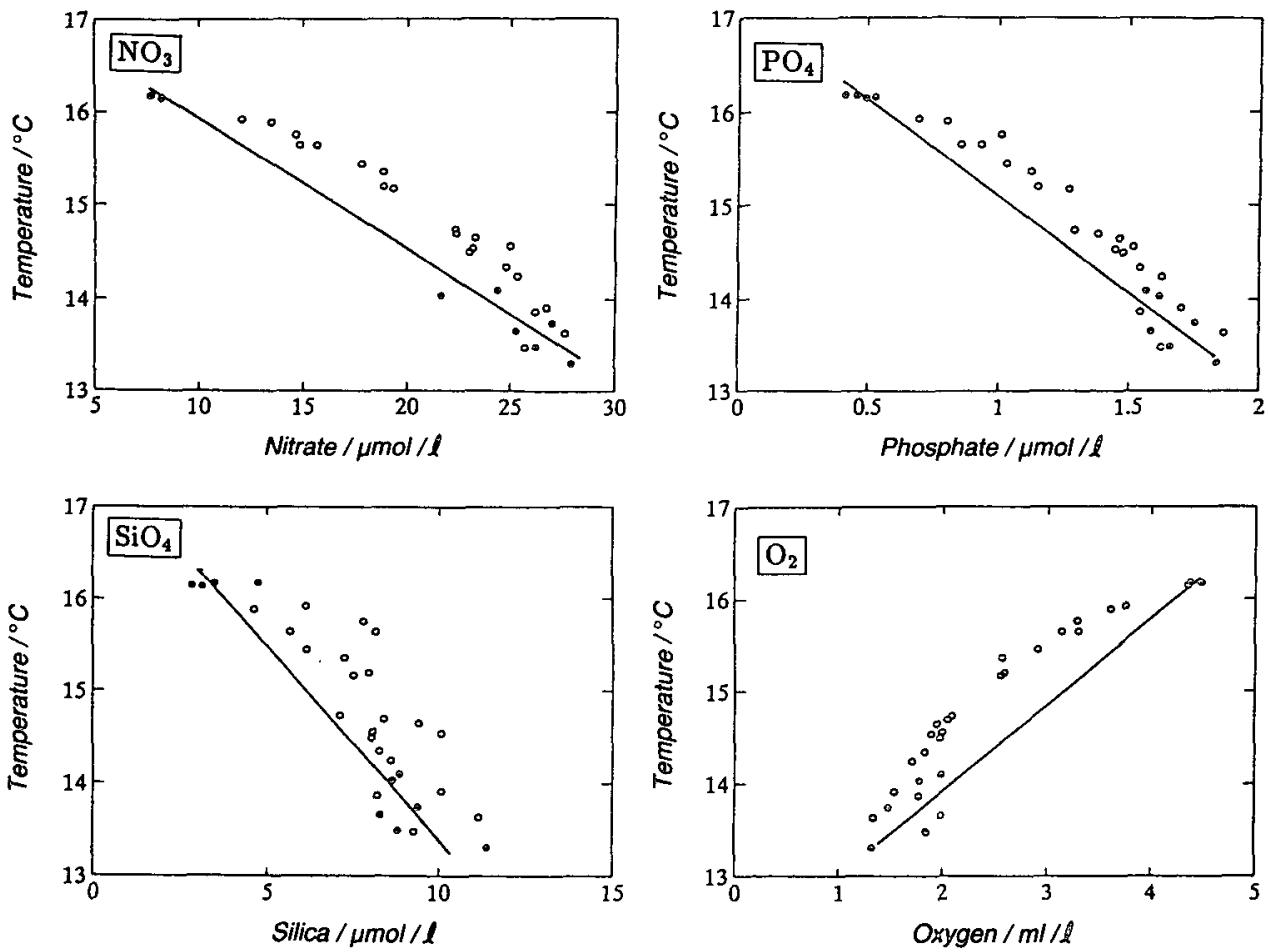

FIG. 2. Temperature-nutrient relationship on the potential density surface 26.7 for Meteor cruise M6 data. Dark dots indicate "pure" NACW and SACW values. The solid line connects the "pure" water data and represents the mixing line for isopycnal mixing.
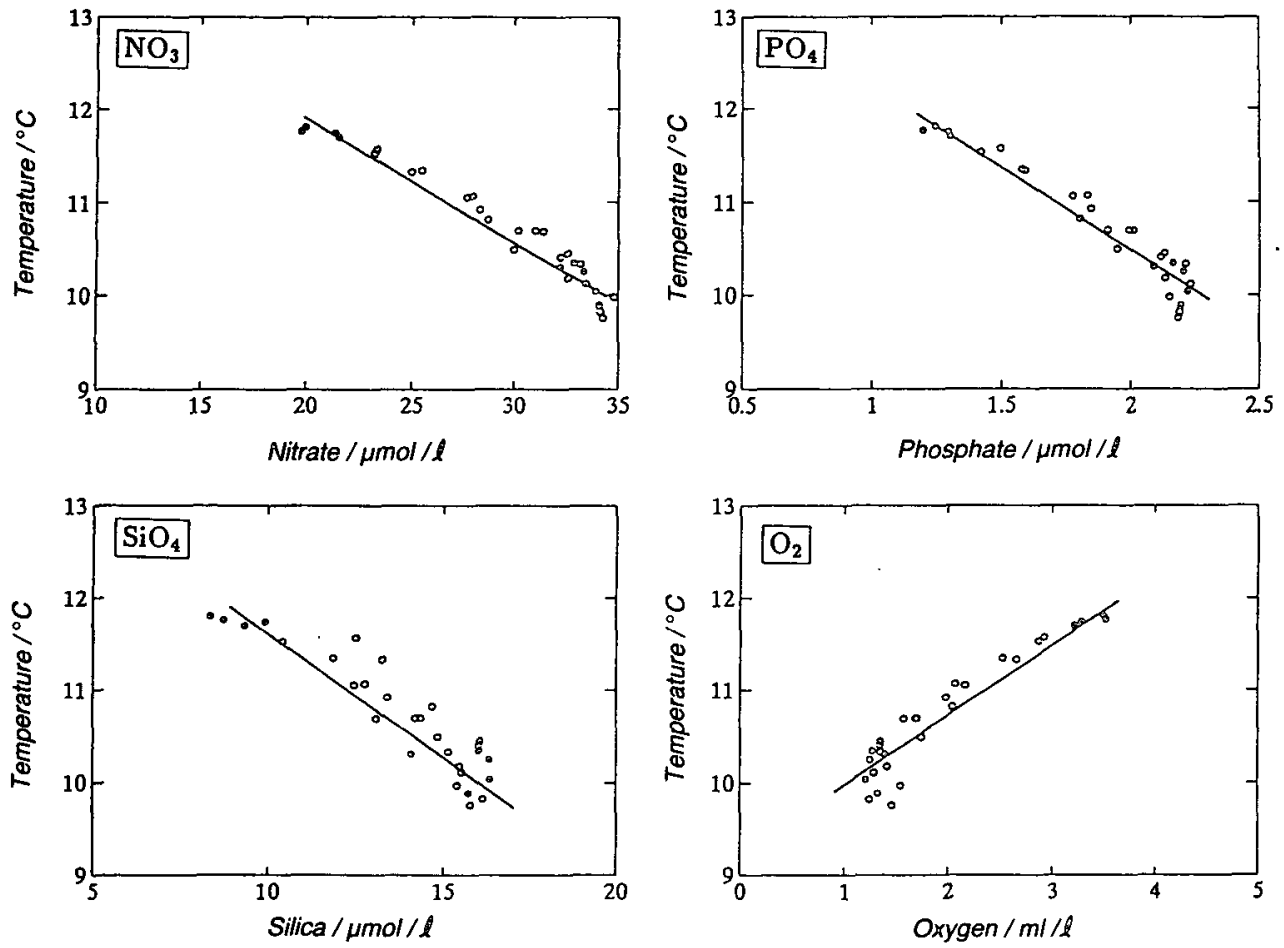

FIG. 3. As in Fig. 2 but for the density surface 27.1. 


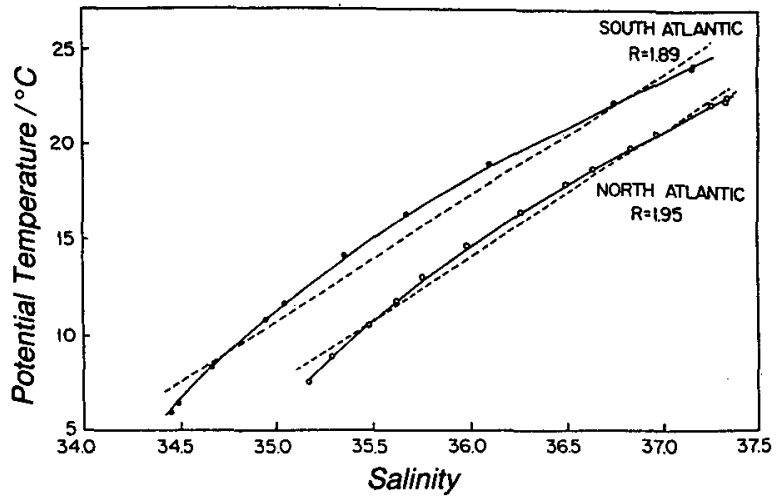

FIG. 4. T-S relationship in the Central Waters of the Atlantic. The solid line represents a curve of constant density parameter $R_{o}$ fitted to the data, while the dashed line represents the best straight line fit (after Schmitt 1981).

nal mixing and to verify the hypothesis that these deviations are caused by double-diffusive processes. This will be done by the use of a multiparameter mixing analysis where we determine fractions of water masses in a given sample from temperature, salinity, and nutrient data without any further specification on the mixing process. The difference between mixing fractions computed by this method to those from classical temperature-salinity $(T-S)$ analysis with the assumption of isopycnal mixing will therefore identify places of diapycnal mixing.

\section{The dataset}

The dataset used for the analysis was collected during three cruises of F.S. Meteor (Fig. 1), which were conducted in 1987-1989 with approximately one year's spacing between respective cruises. The datasets from the first two cruises were obtained during November, while the data from the last cruise represent January/ February conditions. The total dataset consists of 178 CTD stations in the area between the Canary Islands and the Cape Verde Islands. In addition to the CTD measurements, nutrient data were obtained from water samples, including nitrate, phosphate, silica, and dissolved oxygen. The accuracies of the temperature and salinity measurements were estimated to be $\pm 2 \mathrm{mK}$ and \pm 0.002 psu, respectively. Accuracies of the measurements of nitrate, phosphate, silica, and oxygen were $\pm 0.01 \mu \mathrm{mol} \mathrm{L}^{-1}, \pm 0.01 \mu \mathrm{mol} \mathrm{L}^{-1}, \pm 0.05 \mu \mathrm{mol} \mathrm{L}^{-1}$, and $\pm 0.01 \mathrm{ml} \mathrm{L}^{-1}$, respectively.

\section{Evidence for diapycnal mixing processes in the frontal zone}

Isopycnal mixing is generally believed to be dominant in the ocean. In frontal regions and especially at the boundary between the Central Waters, however, diapycnal mixing could make a significant contribution to the mixing process. The data collected during the three Meteor cruises provided a unique chance to investigate this hypothesis.

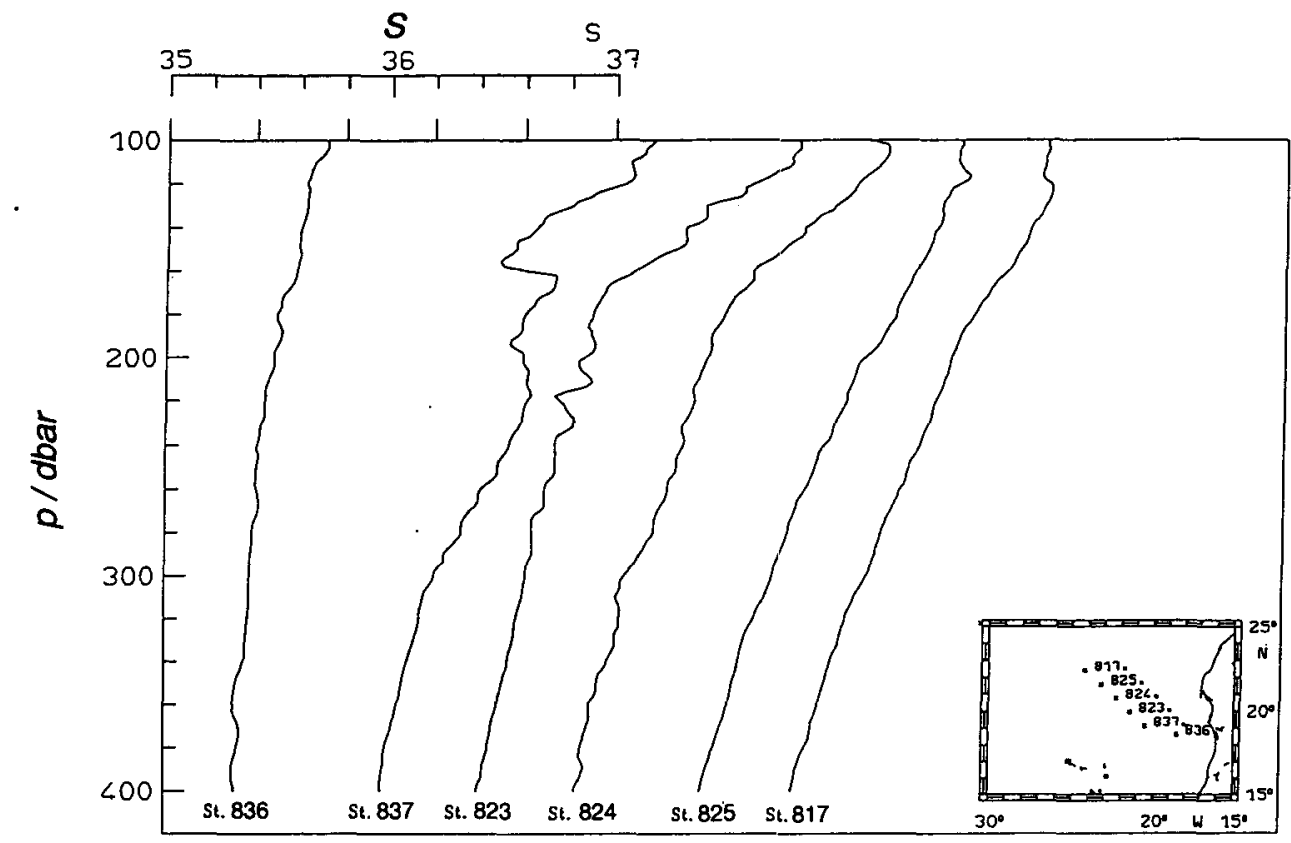

FIG. 5. Section of vertical salinity profiles through the Cape Verde Frontal Zone for Meteor Cruise M6 data. The orientation of the section is shown in the inserted map. Vertical profiles near the front $(837,823$, and 824) show enhanced step structures. 

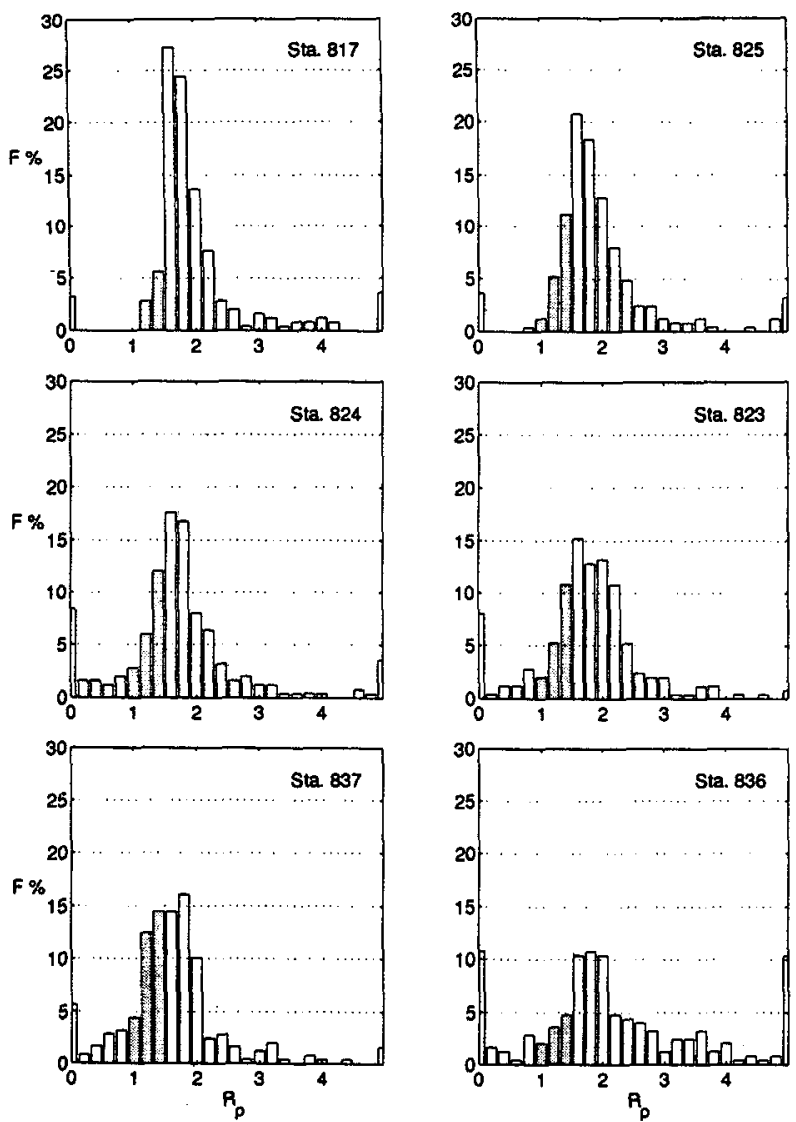

FIG. 6. Frequency distribution of density parameter $R_{\rho}$ on stations along the section shown in Fig. 5. The histograms cover the vertical range of $100-600 \mathrm{~m}$.

An indication that mixing processes in the frontal region cannot be strictly isopycnal was obtained from temperature-nutrient and temperature-oxygen relationships, respectively, on isopycnal surfaces (Figs. 2 and 3). Here $\sigma_{\theta}=26.7$ represents the upper range of the Central Waters with depths corresponding to 150 $250 \mathrm{dbar}$ and $\sigma_{\theta}=27.1$ the lower end with depths corresponding to 400-500 dbar. The full circles mark those data pairs that were observed in the "pure" water masses. "Pure" as used in this context refers to the local definition of the Central Water masses used in this study and will differ from the definitions derived in source regions. If mixing were strictly isopycnal, all observed values would be grouped along the line connecting the "pure" water values. Instead the upperdensity surface shows significant deviations from this line that are consistent for all nutrients and for oxygen. The largest deviations are observed near the front at locations where almost equal amounts of NACW and SACW were found. These are also the stations that showed steplike structures and intrusions in the vertical profiles of temperature and salinity (cf. Figs. 5 and 7).
The deviations from the isopycnal mixing line are most pronounced at the 200-300-dbar level and decrease at greater depth (Figs. 2 and 3 ).

The indications for deviations from isopycnal mixing correspond to earlier results by Schmitt (1981), showing diapycnal processes to be important in maintaining the curved the $T-S$ relationship of the Central Waters. He demonstrated that the curvature in the $T-S$ relationship of the Central Waters (Fig. 4) was consistent with double-diffusive mechanisms, namely salt fingering, and should correspond to constant $R_{\rho}$ values. The shape of the $T-S$ curve as a line of constant density parameter $R_{p}$ is caused by a "feedback" mechanism between the double-diffusive fluxes and $R_{\rho}$. The mixing intensity of salt fingers increases with decreasing $R_{\rho}$, and any deviation from a constant $R_{\rho}$ will therefore cause salt-flux convergences or divergences that remove disturbances in $R_{\rho}$. Two lines are given for comparison in Fig. 4. The dashed line represents the best straightline fit to the data, while the full line gives a curve of constant density parameter $R_{\rho}$. The $R_{\rho}$ value that gave the best fit was 1.89 (1.95, respectively) and is clearly favorable to the straight-line fit.

Another observation in the range of the Central Waters is that their $T-S$ relationship is remarkably tight. Schmitt (1981) was able to explain both the tightness of the $T-S$ relationship of the Central Waters and the constant $R_{\rho}$ character of the curve through double-diffusion. As Stern (1967) has shown, double-diffusion tends to remove $T-S$ anomalies from isopycnal surfaces. Warm and salty anomalies rise through isopycnal surfaces, while cold and fresh anomalies tend to sink. This process will continue until the anomaly has reached an isopycnal that matches its own temperature and salinity values, and this process therefore keeps the $T-S$ relationship tight once it is established.

In Fig. 5 we present vertical profiles of salinity along a section through the frontal zone. Profiles are plotted from southeast to northwest and span the range from the SACW to NACW. Stations 837,823 , and 824 in the frontal zone have steplike structures in the depth range $200-300 \mathrm{~m}$ that are generally considered to be a signature of salt finger activity. Although these steps are more irregular than those observed in the Mediterranean outflow, Schmitt $(1987,1988)$ was able to show that salt finger fluxes can also be important in the irregularly steppy sheets and layers observed in the Central Waters. Step structures as those presented in Fig. 5 are found in the whole area close to the front and are mainly present in the upper level of Central Waters at a depth range between 200 and $300 \mathrm{~m}$.

While salt fingering is possible for a broad range of $1<R_{p}<100$ (Stern 1960), significant influence of salt finger fluxes can only be expected if $R_{\rho}$ is less than 2. This is due to the fact that the growth rate of salt fingers is inversely related to $R_{\rho}$ (Schmitt and Evans 1978) and becomes less than the local Väisälä 


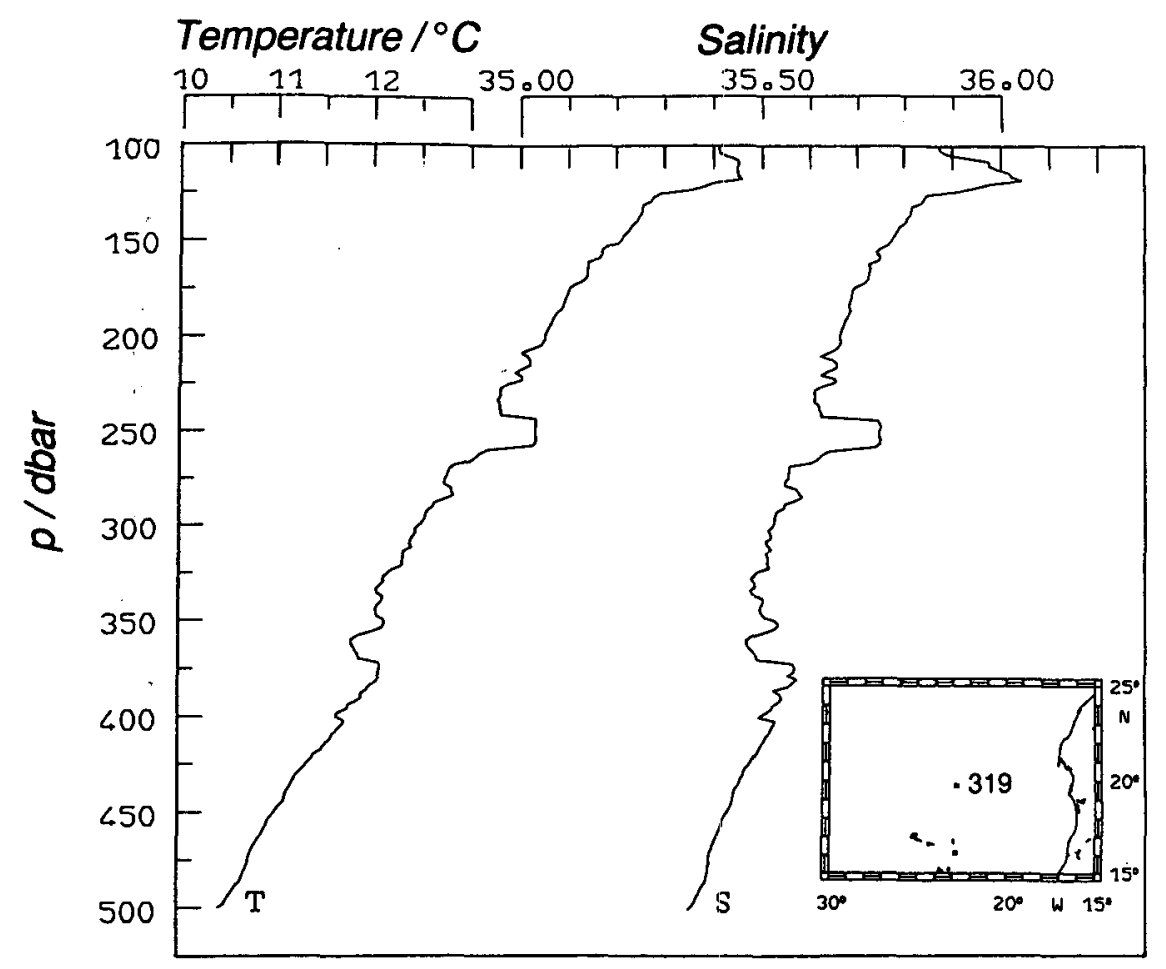

FiG. 7. Temperature and salinity profile in the Cape Verde Frontal Zone showing a large intrusion of warm and saline water in the depth horizon around $250 \mathrm{~m}$.

period only if $R_{\rho}$ is less than 2 . The growth rate will increase further as $R_{\rho}$ decreases towards 1 , with growth rates becoming sufficiently large to produce significant vertical fluxes of heat and mass despite the interference of the internal wave field. Figure 6 shows histograms of $R_{\rho}$ for the depth interval 100$600 \mathrm{~m}$ at stations along the section given in Figure 5. As reported by Schmitt (1981), the majority of $R_{p}$ values in the Central Waters is less than 2 and therefore accomplishes the condition for significant fluxes.

The histograms also show that $R_{\rho}$ values in the depth range $100-600 \mathrm{~m}$ are not exactly constant but vary over a broader range of values. This has several reasons. First, the depth range $100-600 \mathrm{~m}$ comprises part of the water column above the Central Waters as well as waters at the base of this water mass. This adds scatter to the diagram. Second, the smoothness of a vertical profile of $R_{\rho}$ depends critically on the depth interval that is used to compute the temperature and salinity gradients. Very large intervals of 100 dbar as used by Schmitt (1990) result in much smoother $R_{\rho}$ profiles compared to the result with the use of a 4-dbar interval used in this study. And third, the meeting of both Central Waters in the frontal zone and the resulting interleaving causes additional vertical structure and thus scatter in the histograms.
A closer inspection of histograms from those stations showing the step structures (stations 837, 823, and 824) reveals that they have an even higher number of $R_{\rho}$ values near 1 , and a more rapid growth of salt fingers can be expected than in the surrounding fluid. For example, at station $837 R_{\rho}$ values in bins 1.2 and 1.4 have percentages higher than $10 \%$.

The high temperature and salinity differences at the Central Water boundary nearly compensate each other in terms of density. This favors the existence of intrusions along the front. Figure 7 shows an example of a warm and salty intrusion found in our dataset. On both sides of the intrusion double-diffusive fluxes reducè the temperature and salinity gradients. At the upper interface where cold and fresh water is found above warm and salty water, the diffusive form of double-diffusive fluxes will start, while at the lower interface with warm and salty water overlying cold and fresh water, salt fingering sets in. Warm and salty intrusions as shown in Fig. 7 tend to rise through isopycnal interfaces due to the larger transport of salt than heat by the fingers. This represents an effective mechanism of vertical transport. Barton (1987) has observed similar intrusions over the shelf break off Northwest Africa and computed upward buoyancy fluxes in the intrusions that are of similar magnitude to the buoyancy flux at the ocean surface (Schmitt et al. 1989). 


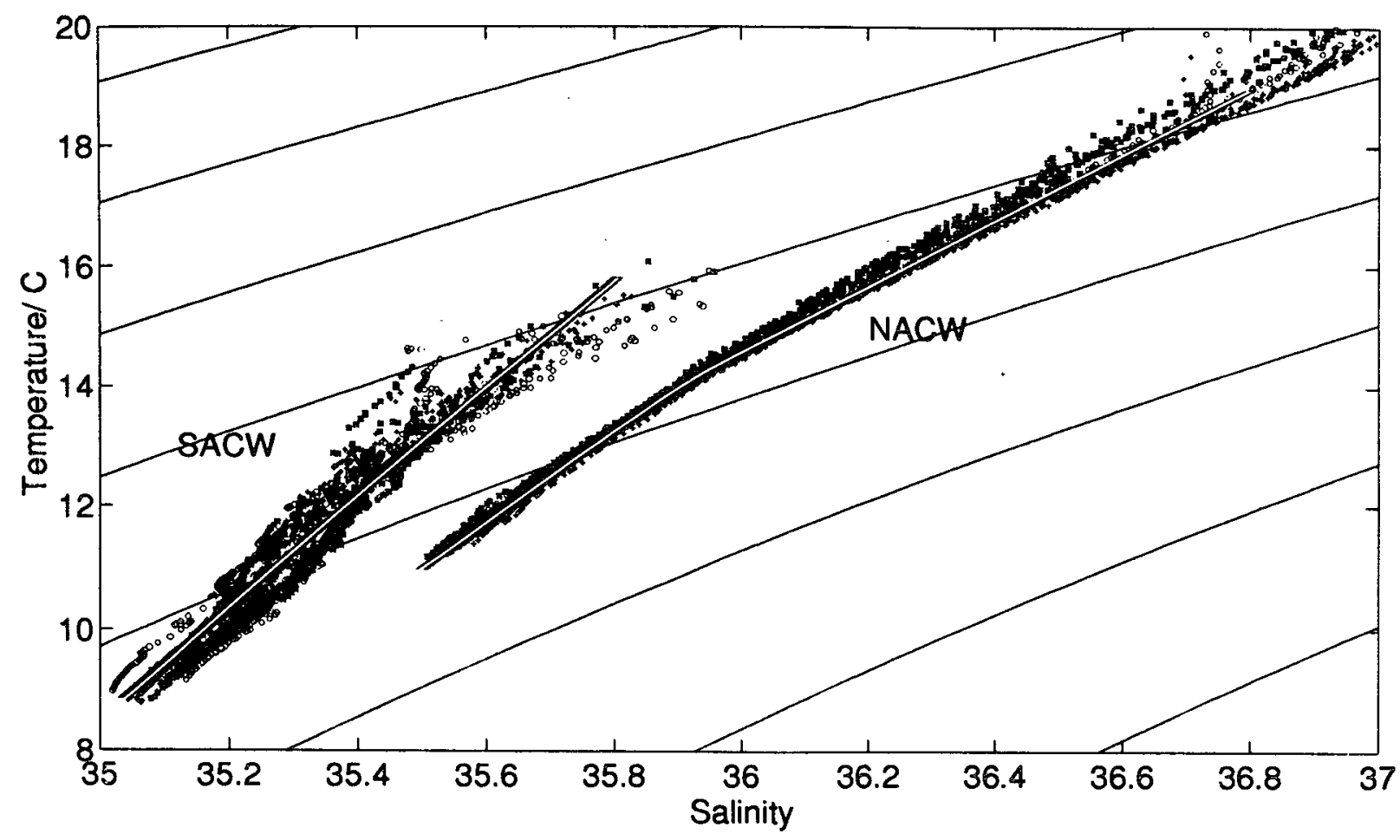

FIG. 8. T-S characteristics of "pure" NACW and SACW for Meteor cruises M4 (*), M6 (+), and M9 (O). Regression lines have been fitted to both Central Waters and are given by heavy white lines. Please note that for NACW the regression curve has been splitted into two parts.

\section{Multiparameter method versus classical $T-S$ analysis}

One way to determine the effect of mixing processes at the frontal boundary is to calculate the water mass fractions of the two source water masses across the front. Since both Central Water masses cover a large temperature and salinity range, they cannot be represented by point sources in the $T-S$ diagram. In the simplest case, each of them can be represented by a line between two $T-S$ pairs, the end points of their respective $T-S$ relationships. A straight-line fit that represents the $T-S$ relationship by its two end points can only be an approximation to the curved $T-S$ relationship of the Central Waters. It is used in order to reduce the number of water types in the mixing analysis to the smallest possible. Since the $T-S$ relationship of the Central Waters is curved very gently, it actually can be considered to be straight for larger sections. Including more water types along a straight part of the $T-S$ curve would only add redundant information to the mixing system, and it is therefore only necessary to include additional water types at inflection points of the $T-S$ curve.

Classical $T-S$ mixing analysis uses only temperature and salinity information and requires additional assumptions in the case that more than three source pairs have to be considered. Otherwise, the associated equation system is underdetermined and no unique solution can be found. The most commonly used constraint to solve the underdetermined equation system implies that mixing only occurs along isopycnals. This usually specifies a unique solution. Since the multiparameter method does not require any assumption on isopycnal or diapycnal mixing, it can be used in comparison with the classical $T-S$ analysis for identifying those regions where diapycnal processes are active.

The multiparameter method is an extension of the classical $T-S$ analysis, which uses additional tracer information to derive an overdetermined or evenly determined linear equation system and thus overcomes the limitation of the classical $T-S$ analysis specifying the mixing direction relative to isopycnals. The most important assumption of the multiparameter analysis is that the observed water masses can be represented by a linear combination of $n$ water types. These water types in turn are specified by certain parameter values of $m$ water properties like temperature, salinity, nutrients, oxygen, etc. A linear equation system is established that uses the information from $m$ tracers to identify the fractions of $n$ water types in a given sample. One has to consider two cases: one in which the number of unknowns equals the number of linear equations, 

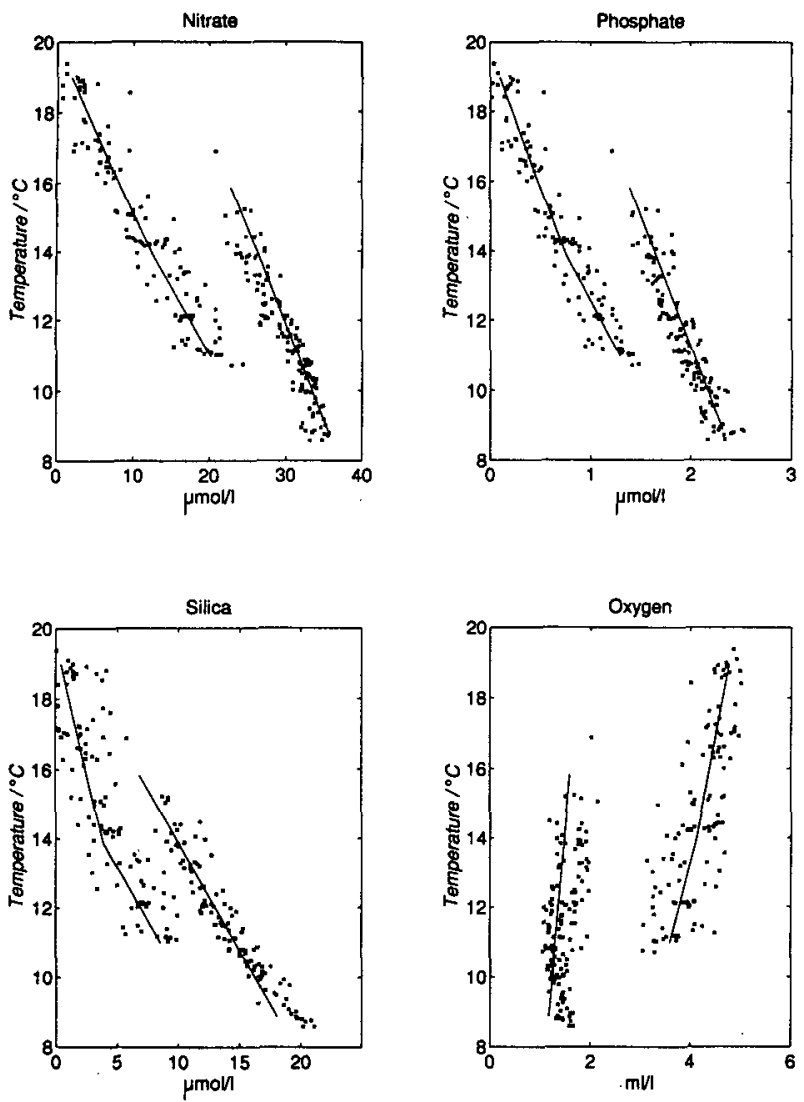

FIG. 9. Temperature-nutrient relationships of "pure" NACW and SACW. The solid lines are computed by linear regression. As for the computation of the $T-S$ relationship, the regression domain for NACW was split into two parts.

and the other where more equations than unknowns exist, that is, the division between an exactly determined and an overdetermined equation system.

Tomczak (1981a) presented the matrix formulation of this water mass analysis method. The mixing problem is given by the matrix equation:

$$
\mathbf{A x}=\mathbf{b} \text {. }
$$

The matrix $\mathbf{A}$ specifies the parameter values defining the water types, for example, temperature, salinity, nu- trients, and oxygen values. If $m-1$ parameters are available defining each of the $n$ water masses, $\mathbf{A}$ has the dimension $m \times n$. The additional $m$ th equation is given by the requirement that the sum of all water mass fractions has to equal $100 \%$, which corresponds to mass conservation. The vector $\mathbf{x}$ has the length $n$ and contains the unknown water mass fractions. The vector $\mathbf{b}$ is of dimension $m$, values $1, \ldots, m-1$ being the observed water mass properties and the $m$ th element representing mass conservation corresponding to the $m$ th row in $\mathbf{A}$.

Tomczak (1981a,b) introduced an application of the multiparameter analysis in the form of the exactly determined system $(m=n)$ and showed first results for the Central Water boundary. In this case the $n$ water mass fractions are determined as an exact solution of a $n$-dimensional linear equation system. The system proved to be sensitive to measurement errors in individual parameters and, together with the lower measurement accuracy of nutrients, leads to the occasional prediction of negative water mass fractions, which are physically meaningless. Although solutions indicated deviations from isopycnal mixing near the frontal zone, the error bars were by far too large to obtain significance.

Mackas et al. (1987) and Tomczak and Large (1989) presented applications of the multiparameter method to open-ocean mixing problems using the overdetermined case $(m>n)$. An overdetermined equation system has no exact solution. An error vector $\mathbf{e}=(\mathbf{A x}$ - b) exists that can be minimized. An often used minimization procedure is that of least-square error, that is, minimizing $\mathbf{e}^{\mathrm{T}} \mathbf{e}$. By this procedure the solution is found that minimizes the contradictions in the information from different parameters. The overdetermined case was used to compute the mixing fractions from our dataset. Compared to the exact solution case of Tomczak (1981a,b), additional modifications of the solution procedure were selected. First, the lower accuracy of the nutrient data compared to temperature and salinity data was incorporated by the use of a weighting matrix according to data accuracy. Second, a physical constraint was put on the solution vector $x$ allowing only positive elements of $\mathbf{x}$, that is, water mass

TABLE 1. Definition of source water types and standard deviations obtained from regression analysis.

\begin{tabular}{|c|c|c|c|c|c|c|}
\hline \multirow[b]{2}{*}{ Parameter } & \multicolumn{3}{|c|}{ NACW } & \multicolumn{2}{|c|}{ SACW } & \multirow[b]{2}{*}{ SD } \\
\hline & Upper & Middle & Lower & Upper & Lower & \\
\hline$T$ & 18.972 & 13.893 & 10.975 & 15.835 & 8.862 & 0.239 \\
\hline$S$ & 36.800 & 35.880 & 35.498 & 35.805 & 35.035 & 0.034 \\
\hline $\mathrm{NO}_{3}$ & 1.819 & 12.610 & 20.196 & 22.833 & 35.499 & 2.170 \\
\hline $\mathrm{PO}_{4}$ & 0.094 & 0.750 & 1.294 & 1.394 & 2.319 & 0.130 \\
\hline $\mathrm{SiO}_{4}$ & 0.439 & 3.855 & 8.590 & 6.850 & 18.027 & 1.540 \\
\hline $\mathrm{O}_{2}$ & 4.776 & 4.117 & 3.598 & 1.586 & 1.171 & 0.410 \\
\hline
\end{tabular}



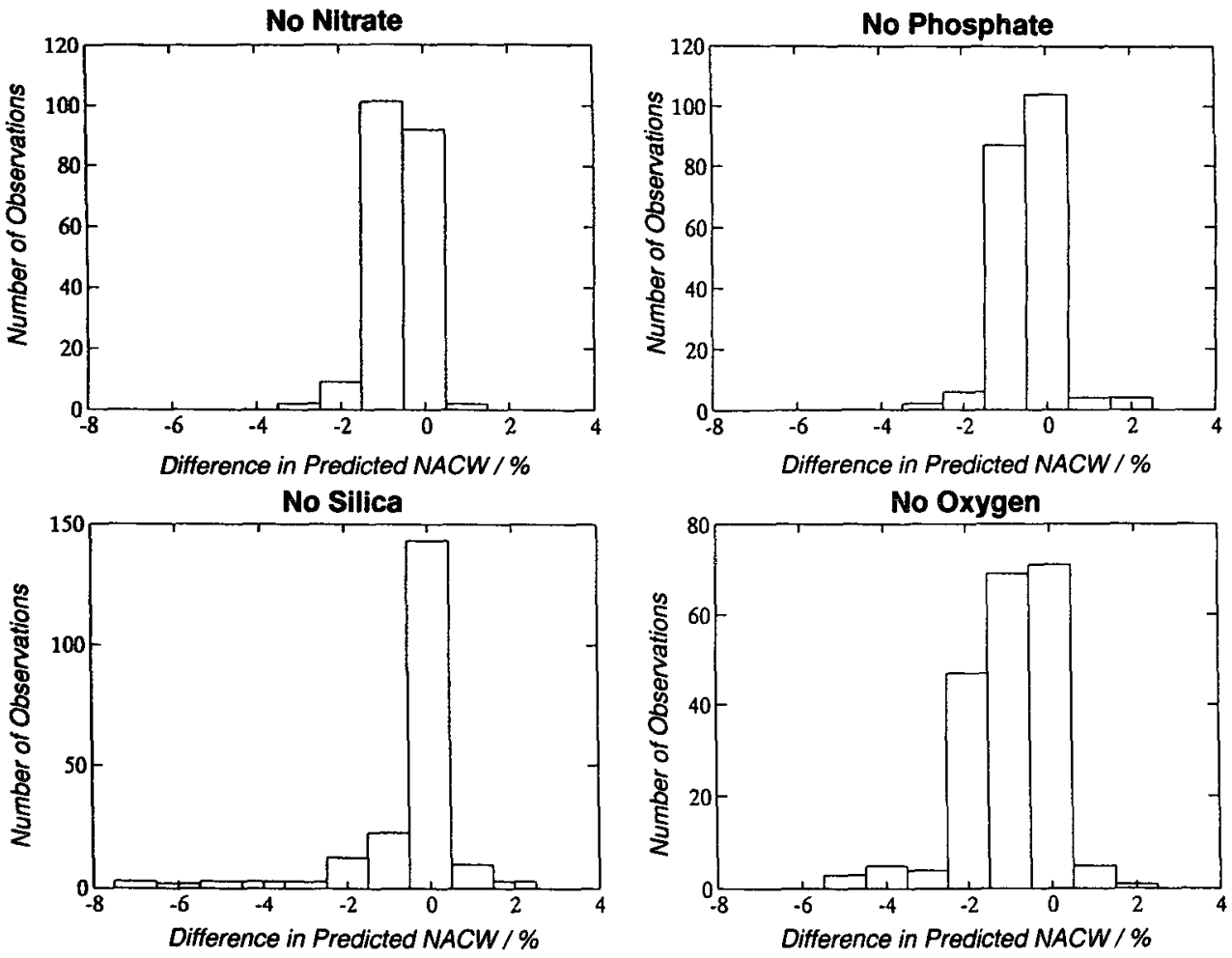

FIG. 10. Stability behavior of the solution vector of the multiparameter analysis with nutrient or oxygen information removed from the equation system. Histograms show the occurrence of changes in the NACW content.

fractions. The solution space is divided into two parts by this constraint, one where the constraint is satisfied and one where it is not. Since we have to pose this constraint on each element of the solution vector, $n$ constraints exist. The solution is found through iteration by the positive least-square algorithm given by Menke (1984), and the reader is referred for more detailed information about the iteration procedure to the articles by Mackas et al. (1987) and Tomczak and Large (1989).

Water types present in the area had to be defined in terms of temperature, salinity, nitrate, phosphate, silicate, and oxygen for the application of the multiparameter method as well as the classical $T-S$ analysis. Since we focused on a local analysis of mixing processes at the Central Water boundary and since both Central Waters change their properties on their way from the source region, a local definition was considered appropriate. Tomczak and Hughes (1980) had derived a local $T-S$ definition of NACW and SACW for the region $20^{\circ}-26^{\circ} \mathrm{N}$ off West Africa. While their definition of $\mathrm{NACW}$ is very similar to the more global one given by Sverdrup et al. (1942), they chose a much saltier type of SACW.

All appropriate station data from Meteor cruises M4, M6, and M9 have been used to obtain a local definition of the Central Waters that will be valid for the geographical area between $15^{\circ}-30^{\circ} \mathrm{N}$ and $15^{\circ}-30^{\circ} \mathrm{W}$. In Fig. 8 we present the observed $T-S$ characteristics of "pure" NACW and SACW. Data in this figure come from stations that have been chosen by their geographical location to best represent the "pure" water masses. The $T-S$ relationship for NACW showed the characteristic curvature corresponding to constant $R_{\rho}$ values and deviated significantly from the linear definition given by Tomczak and Hughes (1980). The observed curvature of the $T-S$ relationship of NACW was approximated by two straight regression lines. The data yielded regression coefficients of 0.99 and 0.97 , respectively. The derived approximate $T-S$ relationships are given in Fig. 8 through heavy white lines.

Due to the smaller range of temperatures and salinities, the curvature of the $T-S$ relationship of SACW is not as distinct as for NACW. The noise ratio of SACW is larger, probably due to enhanced mixing in the equatorial current system. Since the curvature in the $T-S$ relationship was less pronounced, only one straight regression line was fitted to the data, giving a regression coefficient of 0.95 .

Stations that had been used to define the $T-S$ properties of the Central Waters were also used to define the nutrient and oxygen levels of the "pure" water 

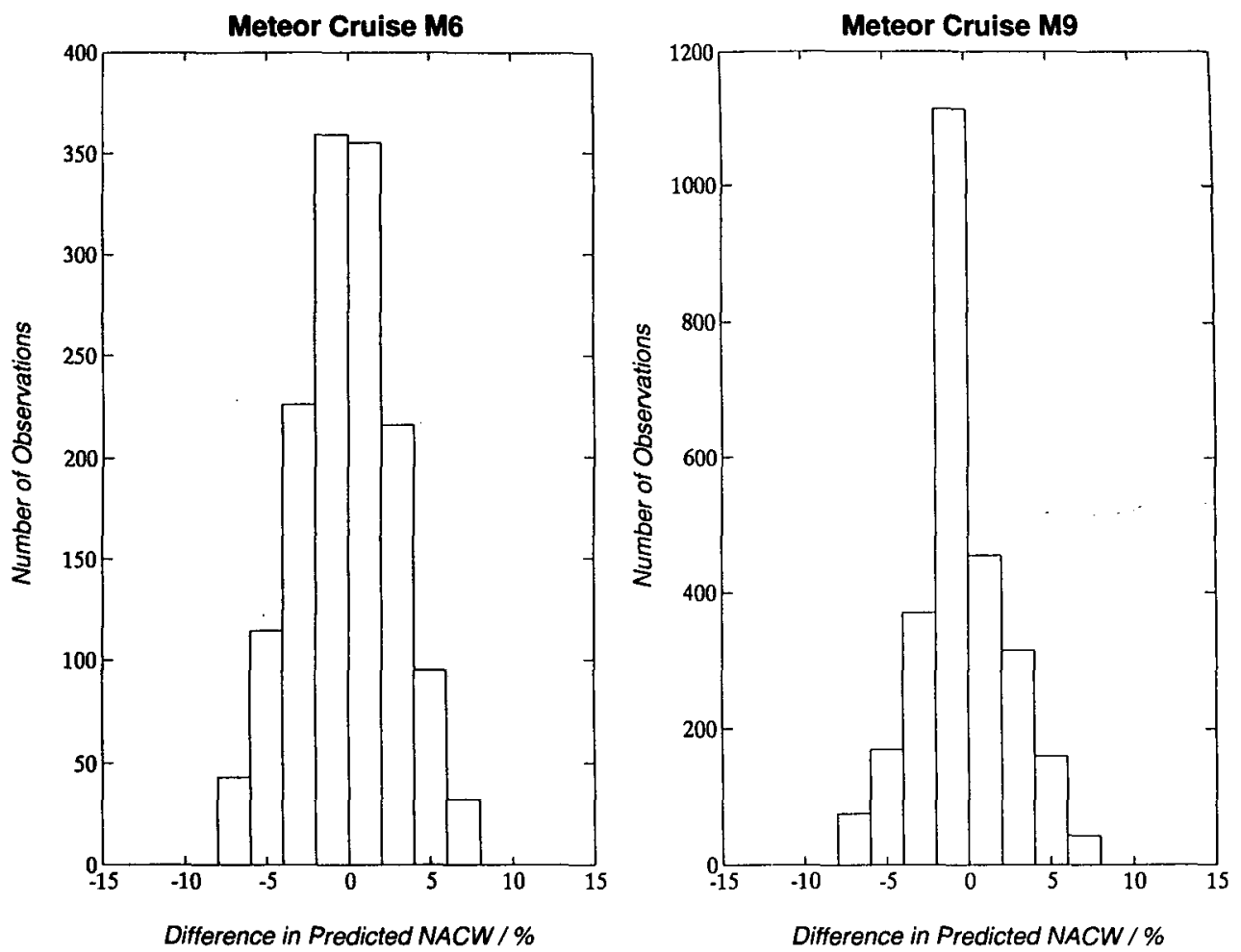

FIG. 11. Stability behavior of the solution vector of the multiparameter analysis with noise added to the data. Uncorrelated white noise with amplitudes of \pm 1 standard deviation was added to all parameters of the data vector. The magnitude of the respective standard deviation is given in Table 1. Histograms show the occurrence of changes in the NACW content.

masses. Figure 9 displays the nutrient and oxygen values of "pure" NACW and SACW. The scatter around the regression lines is much larger than in the case of the corresponding $T-S$ curves. The higher variability can be attributed to environmental variability, biological activity, and lower measurement accuracy. All these factors lead to a lower weighting of nutrient and oxygen information in the mixing analysis. The weights are obtained from the reciprocal $\mathrm{rms}$ values with respect to the regression lines. Note that for NACW the temperature-nutrient and temperature-oxygen parameter ranges have been divided into two parts and two regression lines have been fitted. The regressions yielded the definition values for the parameter matrix $\mathbf{A}$ and the weights. Table 1 gives the resulting source water type definitions and parameter weights.

We first present some sensitivity tests that allow us to estimate the accuracy of the multiparameter estimates as a function of noise in the nutrient data. Two different tests were performed to study the stability of the solution vector. First we tested how much the solution changed when a single source of information was omitted from the equation system. One after the other, all four nutrient equations were dropped from the equation system. The system still remained overdetermined because seven equations had originally been used to determine the five unknown water mass fractions. The change in the predicted NACW content is given in Fig. 10, with the NACW content being the sum of the three NACW water pairs. It can be seen that the predicted NACW content in the water sample varied only slightly through this procedure, and most changes ranged between $\pm 2 \%$. It should be noted that percentage does not refer to a relative error in this context. It is the unit associated with NACW and describes the relative contribution of this water mass in the sample with values ranging from $0 \%$ to $100 \%$. Neglecting the oxygen information as a less well-determined property caused the largest changes in predicted NACW content. But even then most of variations ranged between $\pm 2 \%$.

A more severe test was carried out when the system was additionally disturbed by noise. For this purpose white noise was created that had the range of \pm 1 of the respective standard deviation. White noise, which was uncorrelated for different tracers, was added to the observations. This procedure was repeated 10 times using 10 different values of white noise for each observation. The change in predicted NACW content 

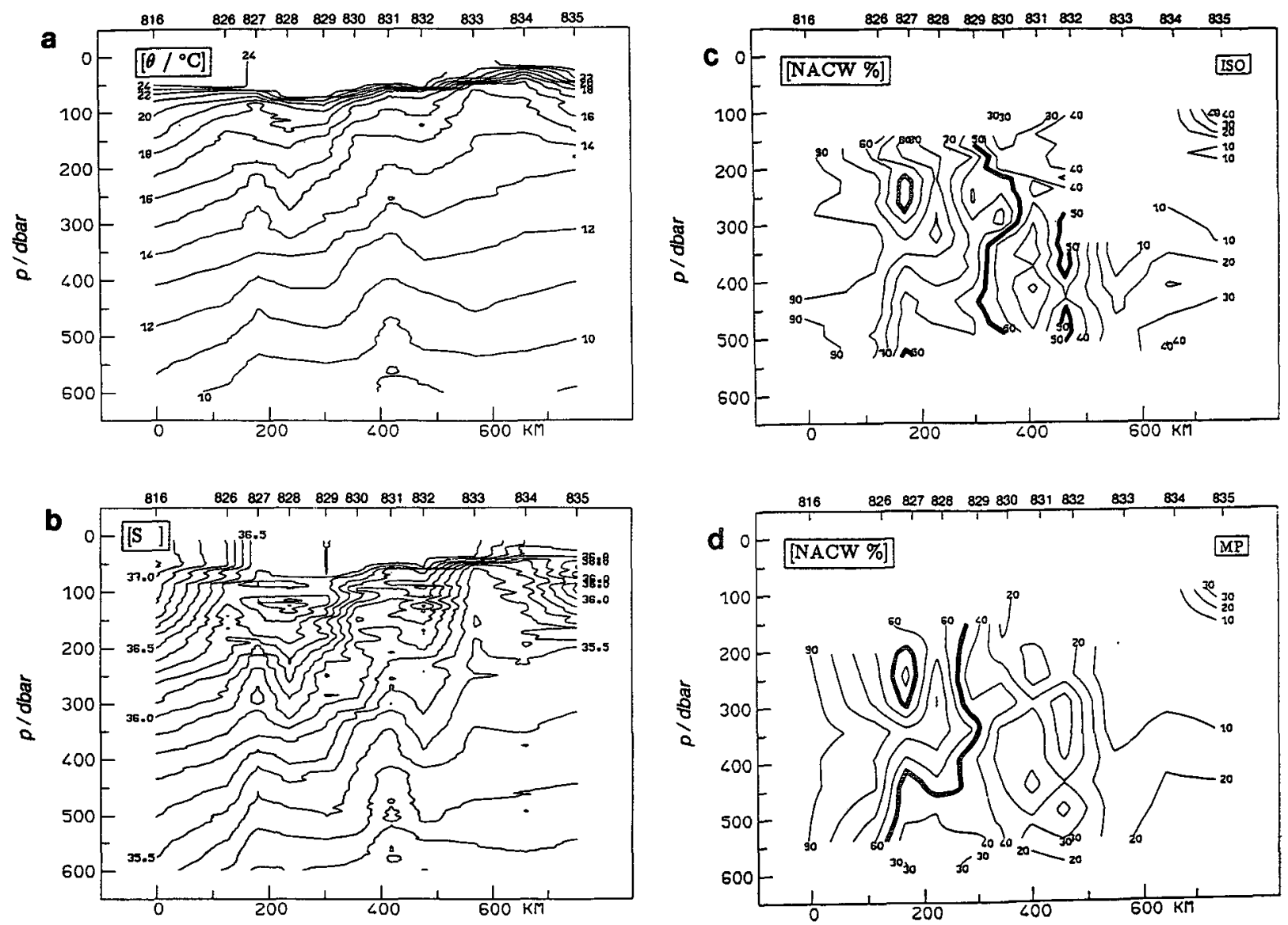

FIG. 12. Sections through the Cape Verde Frontal Zone. No smoothing has been used in contouring the temperature and salinity fields to maintain the complicated vertical structures. Due to this and the much coarser resolution in the horizontal direction, a small amount of structure has been added by the plotting routine in between stations: (a) potential temperature; (b) salinity; (c) NACW content predicted by classical $T-S$ analysis with the assumption of isopycnal mixing: (d) NACW content predicted by the multiparameter method; (e) difference in NACW contents predicted from isopycnal and multiparameter method. The orientation of the section is shown in the inserted map.

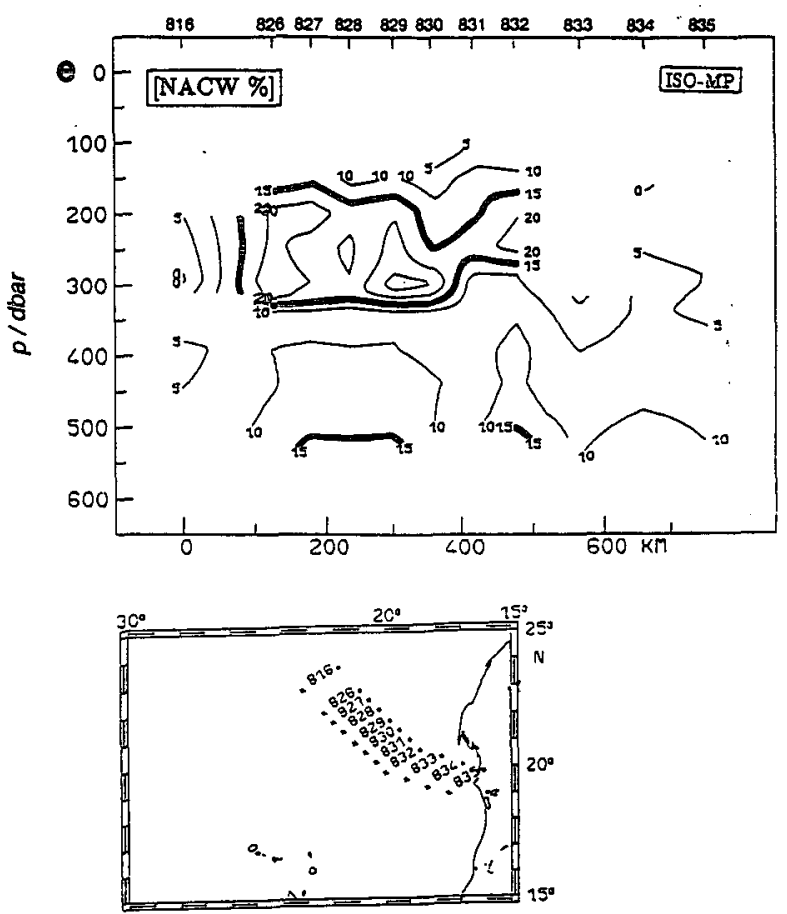



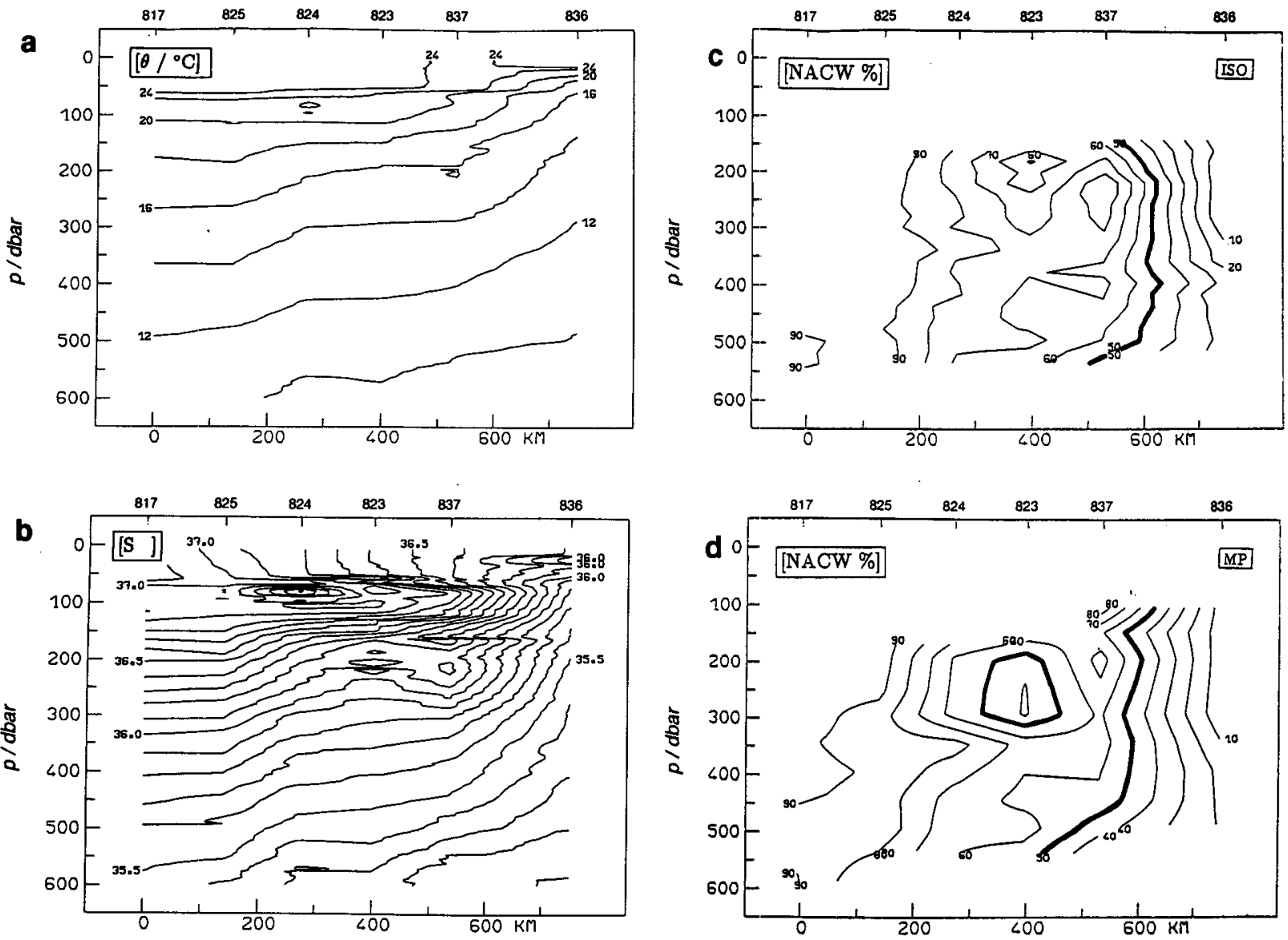

FIG. 13. Sections through the Cape Verde Frontal Zone. No smoothing has been used in contouring the temperature and salinity fields to maintain the complicated vertical structures. Due to this and the much coarser resolution in the horizontal direction, a small amount of structure has been added by the plotting routine in between stations: (a) potential temperature; (b) salinity; (c) NACW content predicted by classical $T-S$ analysis with the assumption of isopycnal mixing; (d) NACW content predicted by the multiparameter method; (e) difference in NACW contents predicted from isopycnal and multiparameter method. The orientation of the section is shown in the inserted map.
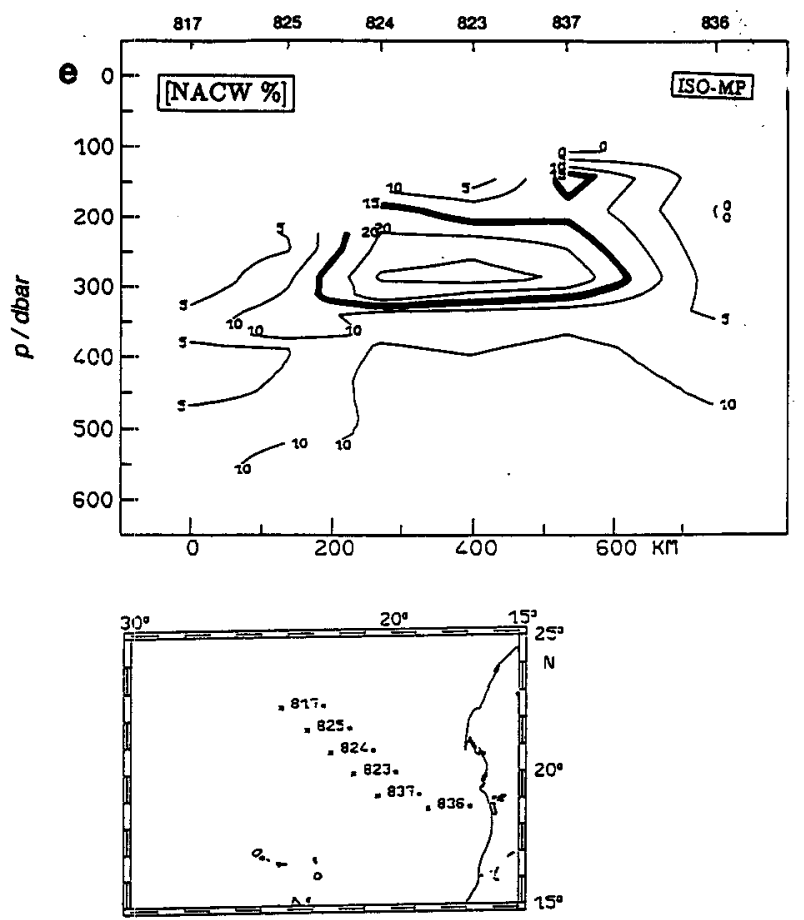

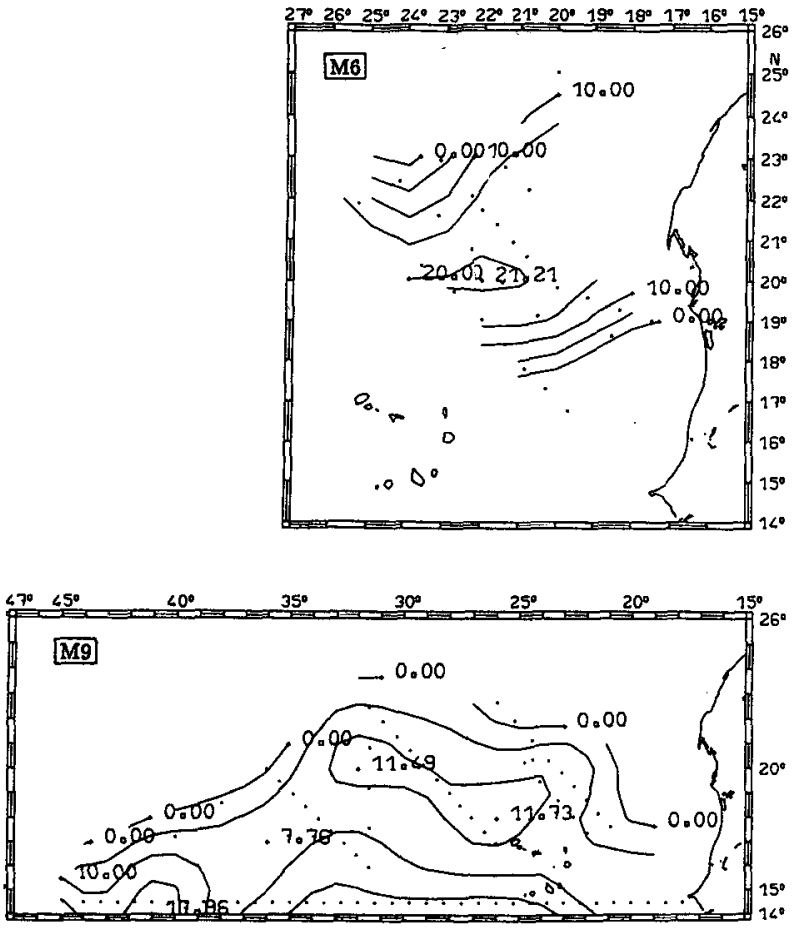

FIG. 14. Differences in predicted NACW content between isopycnal and multiparameter mixing analysis at $250 \mathrm{dbar}$ for Meteor cruises M6 and M9.

is given in Fig. 11 for Meteor cruises M6 and M9. Even after disturbing the system in such a severe manner the observed difference between the original and the disturbed prediction of NACW content ranges only between $-7 \%$ and $+7 \%$, with most values in the range from $-2 \%$ to $+2 \%$. It can therefore be concluded that any deviation in water mass content between isopycnal and multiparameter analysis higher than $10 \%$ is clearly beyond the scatter caused by the noise in the nutrient data and thus represents a significant diapycnal mixing.

\section{Comparison of the multiparameter method with the isopycnal $T-S$ analysis}

Figures $12 \mathrm{a}$ and $12 \mathrm{~b}$ display temperature and salinity distributions along a section through the frontal area. The boundary between NACW and SACW is marked by strongly sloping isotherms and isohalines between stations 829 and 830 . The associated density signal is only weak, approximately one-third of what would be observed if only one of the gradients were present. Maximum salinity and temperature gradients reach values of $0.6 \mathrm{psu}(50 \mathrm{~km})^{-1}$ and $3.0^{\circ} \mathrm{C}(50 \mathrm{~km})^{-1}$, respectively. The fine structure visible in the vertical profiles (cf. Fig. 5) causes the irregular and scattered character of the isolines. The distribution of temper- ature and salinity along this section is even more complicated through numerous intrusions and isolated water parcels, most of them occurring near the front. Closer to the shelf a subsurface doming of isotherms and isohalines was detected. The $T-S$ relationship at the corresponding stations 833 and 834 resembles neither the characteristics of NACW nor SACW. In general, isotherms and isohalines slope upward from northwest to southeast, passing from the warm and saline NACW into the colder and fresher SACW. Different from the conditions observed over the shelf break (Barton 1987), the front is barely detectable at the sea surface. It is masked by a nearly 50 -m-thick homogenous surface layer.

In Fig. 12c we present the results of the isopycnal $T-S$ analysis in terms of water mass composition. The computed NACW fractions correspond closely to the salinity distributions. For example, the low NACW percentages at station 827 in the depth range 200-300 $\mathrm{m}$ are correlated with the upward doming of isohalines at this horizon. Isolated water parcels as apparent in the temperature and salinity sections are present all over the section. The analysis leads to nearly "pure" NACW at the northeastern end of the section and gives the water mass boundary by the $50 \%$ contour between stations 829 and 830 . This result compares well with the often used method of locating the front by the salinity of 36.0 at $150-\mathrm{m}$ depth (Barton 1987). For stations 833 and 834, which did not fit the local $T-S$ characteristics of NACW or SACW, no prediction of water mass composition could be made.

A closer inspection of stations 833 and 834 shows that these stations represent a less salty type of SACW than is found in the surrounding area. To increase the sensitivity of the analysis, the definition of both Central Waters used in this study has been derived locally and is therefore only representing part of the subtropical eastern Atlantic. Comparison of $T-S$ properties and oxygen profiles from the two stations with profiles obtained farther south of the investigation area during Meteor cruise M6 shows that they match characteristics found at about $8^{\circ} \mathrm{N}$. At this latitude the North Equatorial Undercurrent (NEUC) is encountered, which carries SACW eastward into the eastern tropical Atlantic. The water mass found at stations 833 and 834 is thus believed to be a less-diluted form of SACW that is rapidly carried northward along the African coast within the upwelling undercurrent (Hagen and Schemainda 1987) and has its roots within the NEUC. Part of the UUC has been observed to turn into the open ocean near Cap Blanc (Hagen and Schemainda 1987). The two stations therefore do not represent a further water mass in the area but a variety of SACW that differs from the definition used in this study.

At first glance the water mass composition predicted by the multiparameter method (Fig. 12d) looks very similar to that from the isopycnal analysis. This is not 

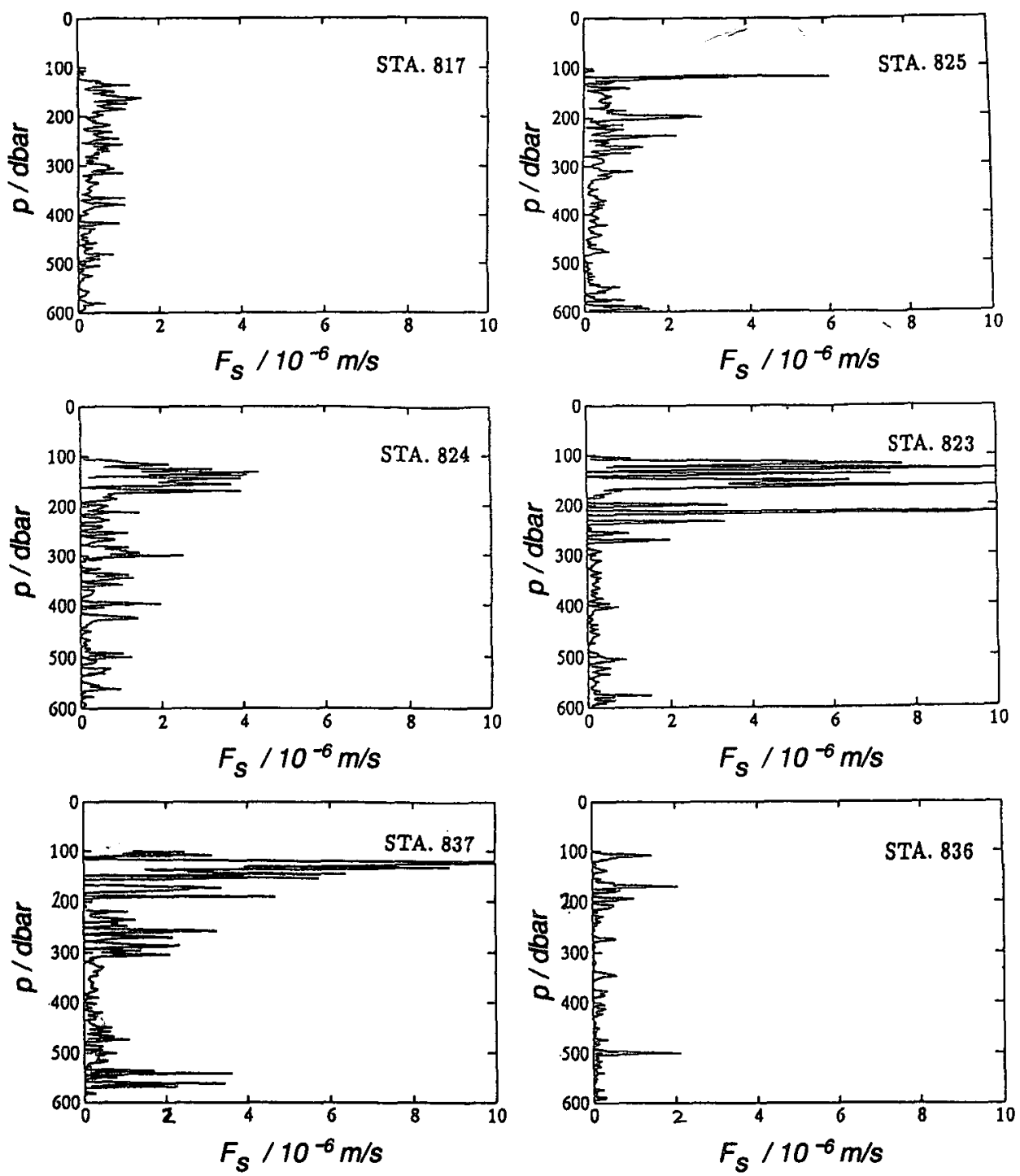

FIG. 15. Profiles of the vertical salt flux $F_{S}$ due to the salt finger form of double-diffusion along the section shown in Fig. 5 .

surprising since the temperature and salinity information received a much higher weight than the nutrient information. Differences between both methods in NACW content (Fig. 12e) can be interpreted as the result of diapycnal mixing, since the classical $T-S$ analysis assumes only isopycnal mixing. Differences up to $25 \%$ occur near the front. The largest deviations are found at depth levels $200-300 \mathrm{~m}$. This is also the

TABLE 2. Haline contribution to the buoyancy flux $\beta F s$ caused by salt finger activity. Values represent means for $100-\mathrm{m}$ segments. Units are $10^{-8} \mathrm{~cm} \mathrm{~s}^{-1}$

\begin{tabular}{|c|c|c|c|c|c|c|}
\hline $\begin{array}{l}\text { Depth range } \\
(\mathrm{m})\end{array}$ & $\begin{array}{c}\text { Station } \\
817\end{array}$ & $\begin{array}{l}\text { Station } \\
825\end{array}$ & $\begin{array}{c}\text { Station } \\
824\end{array}$ & $\begin{array}{c}\text { Station } \\
823\end{array}$ & $\begin{array}{c}\text { Station } \\
837\end{array}$ & $\begin{array}{l}\text { Station } \\
836\end{array}$ \\
\hline $200-300$ & 2.1 & 2.4 & 3.3 & 5.8 & 4.0 & 0.6 \\
\hline $300-400$ & 1.2 & 1.5 & 2.4 & 0.9 & 1.8 & 0.4 \\
\hline $400-500$ & 1.1 & 1.2 & 1.7 & 0.8 & 1.5 & 0.6 \\
\hline
\end{tabular}


TABLE 3. Double-diffusive thermal, haline, and buoyancy fluxes $F_{T}, F_{S}$, and $F_{\rho}$, respectively, through a warm and salty intrusion. The buoyancy flux is defined as $F_{p}=-\rho\left(\alpha F_{T}-\beta F_{S}\right)$.

\begin{tabular}{lcccccc}
\hline \hline & $\begin{array}{c}\Delta T \\
\left({ }^{\circ} \mathrm{C}\right)\end{array}$ & $\Delta S$ & $R_{\rho}$ & $\begin{array}{c}F_{T} \\
\left(10^{-5}{ }^{\circ} \mathrm{C} \mathrm{m} \mathrm{s}^{-1}\right)\end{array}$ & $\begin{array}{c}F_{S} \\
\left(10^{-5} \mathrm{psu} \mathrm{m} \mathrm{s}^{-1}\right)\end{array}$ & $\begin{array}{c}F_{\rho} \\
\left(10^{-7} \mathrm{~g} \mathrm{~cm}^{-2} \mathrm{~s}^{-1}\right)\end{array}$ \\
\hline Diffusive & 0.481 & 0.132 & 1.5 & 1.8 & 0.3 & 4.8 \\
Salt fingering & 0.523 & 0.186 & 1.3 & 5.4 & 2.1 & -1.7 \\
\hline
\end{tabular}

range where step structures in the vertical profiles of temperature and salinity, intrusions, and the distribution of $R_{p}$ were suggestive of double-diffusive processes being sufficiently strong to provide significant diapycnal fluxes. As indicated by the error analysis, the differences above $10 \%$ in predicted NACW content found here exceed the effect of the noise introduced by the nutrient scatter.

A second example of the structure of the frontal zone is given in Fig. 13. This section has a lower spatial resolution than the previous one. Most parts of the sections are characterized by high NACW fractions, and the transition into the SACW regime only occurs near the southern end of the area (Figs. 13a,b). Most of the fine structure visible in the section is confined to the frontal zone.

Again the water mass composition predicted from the isopycnal mixing analysis looks similar to the multiparameter results (Figs. 13c,d). Both methods locate the water mass boundary between stations 837 and 836. From these calculations it can be seen that the fine structure observed at stations 823 and 824 is related to an intrusion of NACW at 300-m depth, which was overlayed by an isolated water parcel with extremely high amounts of SACW. A plot of differences in predicted NACW content (Fig. 13e) reveals that highest deviations are found between 200 and $300 \mathrm{~m}$ and at stations near the front. Differences in this depth range are as high as $25 \%$, and the lower NACW content predicted by the multiparameter method is consistent with the observed slope of the temperature-nutrient relationships on isopycnals.

In a horizontal plane (Fig. 14) we find a concentration of large deviations between the results of the classical $T-S$ and the multiparameter analysis in an elongated patch running northeast-southwest. This structure coincides with the mean orientation of the Central Water boundary during the two observation periods. Deviations calculated from Meteor cruise M6 data are higher than those from Meteor cruise M9 data. The latter of the two cruises was conducted in late winter, and the gradients in temperature and salinity were much weaker during that period. Since the objective analysis tends to smooth the property distributions, the actual differences calculated are even higher than the values shown in Fig. 14 and reach values above $15 \%$ for Meteor cruise M9.

\section{Diapycnal fluxes in the frontal region}

The double-diffusive heat and salt fluxes presented in the following are computed with laboratory derived flux laws. Turner (1968) was one of the first to determine experimentally the fluxes of heat and salt through a fingering interface. His measurements supported the $4 / 3$ power laws that had been derived on the basis of dimensional analysis. The haline buoyancy flux $\beta F_{S F}$ through a fingering interface is given by

$$
\beta F_{S F}=\left(g k_{T}\right)^{1 / 3} C_{F}\left(R_{\rho}\right)\left(\beta \Delta S_{F}\right)^{4 / 3},
$$

with $g$ being the acceleration due to gravity, $k_{T}$ the thermal diffusivity, and $\Delta S$ the salinity difference across the interface. The subscript $F$ indicates that the formula is valid only for the fingering interface. The empirical coefficient $C_{F}$ is itself a function of density parameter $R_{\rho}$ and was determined by Schmitt (1981) to be

$$
C_{F}\left(R_{\rho}\right)=0.05+0.3 R_{\rho}^{-3} .
$$

The thermal contribution to the buoyancy flux across the interface can be expressed as a ratio of the haline flux. Estimates of this flux ratio $r_{F}$ (Turner 1968; Schmitt 1979) show it to be dependent on $R_{\rho}$, with approximately 0.7 for $R_{\rho}$ values less than 2.5 and decreasing to 0.58 for $R_{\rho}$ between 2.5 and 4.0. Huppert (1971) showed that in the diffusive case the thermal buoyancy flux follows a similar 4/3 power law as the haline buoyancy flux in the fingering case. He estimated the associated coefficients to be

$$
\alpha F_{T D}=0.32\left(k_{T}\right)^{2 / 3}\left(\frac{g}{\nu}\right)^{1 / 3}\left(\alpha \Delta T_{D}\right)^{4 / 3} R_{\rho D}^{-2}
$$

with $\nu$ being the kinematic viscosity and subscript $D$ denoting the diffusive case.

In the diffusive case the haline buoyancy flux can again be expressed as a fraction of the thermal flux, and the ratio was determined by Huppert (1971) to be

$$
\begin{array}{rll}
\beta F_{S D}=\left(1.85-0.85 R_{\rho D}\right) \alpha F_{T} & \text { for } & 1 \leqslant R_{\rho D} \leqslant 2 \\
\beta F_{S D}=0.15 \alpha F_{T D} & \text { for } & R_{\rho D}>2,
\end{array}
$$

with $R_{\rho D}$ being simply the inverse of $R_{\rho}$.

Figure 15 shows vertical profiles of the salt flux caused by salt fingering. The highest values of doublediffusive salt flux occur at stations 824,823 , and 837 , where the distributions of the density parameter $R_{\rho}$ (cf. 
Fig. 6) indicated that the time evolution of the fluxes would be sufficiently fast to overcome the internal wave field effects. The largest salt fluxes also occur at stations where the comparison of the multiparameter method and the classical $T-S$ analysis lead to higher deviations from isopycnal mixing (cf. Fig. 13).

Mean values for the haline contribution to the buoyancy flux $\beta F_{S}$ in 100-m segments are given in Table 2. Schmitt and Evans (1978) have calculated the haline buoyancy flux from CTD measurements in the western tropical Atlantic between 200 and $700 \mathrm{~m}$. They calculated fluxes between 2.7 and $0.5 \times 10^{-8} \mathrm{~cm} \mathrm{~s}^{-1}$ from their dataset, which correspond to $12 \%$ of the buoyancy forcing at the surface.

Schmitt and Evans (1978) used a different technique to calculate the double-diffusive fluxes over a $100-\mathrm{m}$ segments from fine structure profiles with special regard to the intermittency of the salt-fingering process due to the internal wave activity. Current meter data have shown that internal waves are important in the observation area (Siedler and Finke 1993; Siedler and Paul 1991). Schmitt and Evans (1978) attributed in their calculations each $100-\mathrm{m}$ segment with one characteristic salinity difference $\Delta S$ that represented the highgradient regions within the segment and an intermittency factor that represents the ratio of high- to lowgradient regions. A similar technique could not be applied to our data due to lack of vertical resolution. We therefore chose to calculate the fluxes at every depth interval with a $100-\mathrm{m}$ segment individually and averaged them finally over the whole segment, thus smoothing over the effects of high- and low-gradient regions. Our calculations will therefore produce slightly higher estimates than the technique of Schmitt and Evans (1978) since we include the contribution of salt fluxes from the small gradient regions even though they are small in magnitude.

Values in Table 2 are of similar magnitude as those observed by Schmitt and Evans (1978). The average of all values listed in Table 2 would correspond to $20 \%$ of the surface forcing, which is less than $10^{-7} \mathrm{~cm} \mathrm{~s}^{-1}$ in the eastern Atlantic. It should be kept in mind, however, that the laboratory flux laws used for the calculation of the fluxes are likely to overestimate the fluxes. Nonetheless, the magnitude of these fluxes suggests that double-diffusive fluxes are important in this area.

Large double-diffusive fluxes are also associated with intrusive features that appear in the whole frontal area. An example is shown in Fig. 7. Both types of doublediffusive fluxes occur on the top and bottom of an intrusion, with the upper surface driven by the diffusive type of double-diffusion and the lower surface by salt fingering. For the intrusion shown in Fig. 7 the contribution of both types of fluxes to the buoyancy flux are listed in Table 3 . The resulting upward buoyancy flux is $3.1 \times 10^{-7} \mathrm{~g} \mathrm{~cm}^{-2} \mathrm{~s}^{-1}$ and compares well with buoyancy fluxes calculated for similar features on the shelf break. Barton (1987) reports buoyancy fluxes of $3 \times 10^{-7} \mathrm{~g} \mathrm{~cm}^{-2} \mathrm{~s}^{-1}$ for an $80-\mathrm{km}$ long intrusion found over the continental slope. The order of magnitude of these fluxes is as high as the buoyancy forcing at the sea surface through the combined effects of heat flux and evaporation-precipitation. Schmitt et al. (1989) calculated values between 2 and $6 \times 10^{-7} \mathrm{~g} \mathrm{~cm}^{-2} \mathrm{~s}^{-1}$ for our area of investigation. Again it has to be kept in mind that the use of laboratory flux laws is likely to overestimate the actual fluxes and that the obtained values should therefore be viewed as upper bounds to the fluxes.

\section{Conclusions}

The comparison of results from the multiparameter method with results from the usual isopycnal water mass analysis allows one to distinguish between the effects of isopycnal and diapycnal mixing. The NACW content computed with the assumption of isopycnal mixing can deviate up to $30 \%$ from estimates derived by the multiparameter method. These differences are larger than the uncertainties introduced by the noise level in the nutrient and oxygen data and therefore prove the presence of diapycnal mixing. Maximum differences occur in the frontal region at the depth horizons $200-300 \mathrm{~m}$. We also find accumulations of the associated $R_{p}$ values near 1 , corresponding to high growth rates of salt fingers. These large rates ensure that the associated fluxes will only be interrupted intermittently by internal wave effects. Both the buoyancy fluxes due to salt fingers and those due to upwardmoving intrusions are of magnitudes that are comparable to the surface buoyancy-forcing terms. Doublediffusive fluxes will therefore have a significant influence on the vertical balances of heat and salt in the Central Water boundary area.

Acknowledgments. The authors appreciated the assistance in data collection and processing by the staff of the Marine Physics Departement of the Institut fur Meereskunde, Kiel, and the help of the captains and crew of F.S. Meteor. We have benefitted from discussions with M. Tomczak Jr. and R. W. Schmitt. The authors would like to thank Barbara Gaffron for her careful preparation of the manuscript. The study was part of the research program "Warmwassersphäre des Atlantiks" (SFB 133), which is funded by the Deutsche Forschungsgemeinschaft.

\section{REFERENCES}

Barton, E. D., 1987: Meanders, eddies and intrusions in the thermohaline front off Northwest Africa. Oceanol. Acta, 10(3), 267283.

Bauer, E., and G. Siedler, 1988: The relative contributions of advection and isopycnal and diapycnal mixing below the subtropical salinity maximum. Deep-Sea Res., 35, 811-837.

Gregg, M. C., 1975: Oceanic fine and microstructure. Rev. Geophys. Space Phys., 13(3), 586-591. 
Hagen, E., and R. Schemainda, 1987: On the zonal distribution of South Atlantic Central Water (SACW) along a section off Cape Blanc, Northwest Africa. Proceedings, International Symp. on Equatorial Vertical Motion, Paris, Oceanol. Acta., 61-70.

,-- N. Michelchen, W. Zahn, G. Wolf, D. Nehring, and U. Brenning, 1986: Quasistationäre Strukturen im Wasserauftrieb vor Mauretanien im März/April 1983. Beitr. zur Meereskunde, 54, 19-31.

Hogg, N. G., E. J. Katz, and T. B. Sandford, 1978: Eddies, islands and mixing. J. Geophys. Res., 83, 2921-2938.

Huppert, H. E., 1971: On the stability of a series of double diffusive layers. Deep-Sea Res., 18, 1005-1021.

Lambert, R. B., and W. Sturges, 1977: A thermohaline staircase and vertical mixing in the thermocline. Deep-Sea Res., 24, 211-222.

Mackas, D. L., K. L. Denman, and A. F. Bennett, 1987: Least squares multiple tracer analysis of water mass composition. J. Geophys. Res., 92(C3), 2907-2918.

Manriquez, M., and F. Fraga, 1982: The distribution of water masses in the upwelling region off Northwest Africa in November. Rapp. P.-v. Réun. Cons. Int. Explor. Mer, 180, 39-47.

Menke, W., 1984: Geophysical Data Analysis, Discrete Inverse Theory. Academic Press, 260 pp.

Onken, R., and B. Klein, 1991: A model of baroclinic instability and waves between the ventilated gyre and the shadow zone of the North Atlantic. J. Phys. Oceanogr., 21 (1), 53-67.

Schmitt, R. W., 1979: Flux measurements on salt fingers at an interface. J. Mar. Res., 37(3), 419-436.

- 1981: Form of the temperature-salinity relationship in the central water: Evidence for double diffusive mixing. J. Phys. Oceanogr., 11, 1015-1026.

—- 1987: The Caribbean Sheets and Layers Transects (C-SALT) Program. Eos, Trans. Amer. Geophys. Union, 68(5), 57-60.

- 1988 : Mixing in a thermohaline staircase. Small-Scale Turbulence and Mixing in the Ocean. J. C. J. Nihoul and B. M. Jamart, Eds., Elsevier, 435-452.

- 1990: On the density balance in the central water. J. Phys. Oceanogr., 20, 900-906.
—, and D. L. Evans, 1978: An estimate of vertical mixing due to salt fingers based on observations in the North Atlantic Central Water. J. Geophys. Res., 83(C6), 2913-2919.

-, P. S. Bogden, and C. E. Dorman, 1989: Evaporation minus precipitation and density fluxes for the North Atlantic. J. Phys. Oceanogr., 19, 1208-1221.

Siedler, G., and U. Paul, 1991: Barotropic and baroclinic tidal currents in the eastern basins of the North Atlantic. J. Geophys. Res., 96(12), 22 259-22 271.

—, and M. Finke, 1993: Long-period transport changes in the eastern North Atlantic and their simulation by propagating waves. J. Geophys. Res., 98(2), 2393-2406.

Stern, M. E., 1960: The "Salt-Fountain" and thermohaline convection. Tellus, XII, 172-175.

_ 1967: Lateral mixing of water masses. Deep-Sea Res., 14, 747753.

Sverdrup, H. U., M. W. Johnson, and R. H. Fleming, 1942: The Oceans: Their Physics, Chemistry and General Biology. Prentice Hall, 1087 pp.

Tait, R. I., and M. R. Howe, 1968: Some observations of thermocline stratification in the deep ocean. Deep-Sea Res., 15, 275-280.

Tomczak, M., Jr., 1981a: A multi-parameter extension of temperature/ salinity diagram techniques for the analysis of non-isopycnal mixing. Progress Oceanogr., Vol. 10, Pergamon, 141-171.

, 1981b: An analysis of mixing in the frontal zone of South and North Atlantic Central Water off North-West Africa. Progress Oceanogr., Vol. 10, Pergamon, 173-192.

$\longrightarrow$, and P. Hughes, 1980: Three dimensional variability of water masses and currents in the Canary Current upwelling region. "Meteor" Forschungsergebnisse, A21, 1-24.

—, and D. G. B. Large, 1989: Optimum multiparameter analysis of mixing in the thermocline of the eastern Indian Ocean. $J$. Geophys. Res., 94(C11), $16141-16149$.

Turner, J. S., 1968: The behaviour of a stable gradient heated from below. J. Fluid Mech., 33, part 1, 183-200.

Zenk, W., B. Klein, and M. Schroeder, 1991: Cape Verde Frontal Zone. Deep-Sea Res., 38, Suppl. 1, S505-\$530. 